\title{
Switch to restoration therapy in a testosterone treated central hypogonadism with erythrocytosis
}

\author{
B Cangiano',2, C Cacciatore1,2, L Persani1,2 and M Bonomi1,2 \\ 1Division of Endocrine and Metabolic Diseases, IRCCS Istituto Auxologico Italiano, Milan, Italy and 2Department of \\ Clinical Sciences and Community Health, University of Milan, Milan, Italy
}

\author{
Correspondence \\ should be addressed \\ to M Bonomi \\ Email \\ m.bonomi@auxologico.it
}

\section{Summary}

We describe a case of severe erythrocytosis caused by testosterone replacement therapy in a 66-year-old man affected with hypogonadotropic hypogonadism $(\mathrm{HH})$ determining osteoporosis, resolved by switching to restoration therapy with clomiphene citrate. The patient complained fatigue, loss of libido and defective erections and a spontaneous vertebral fracture despite bisphosphonate therapy and vitamin D supplementation. The examinations proved isolated $\mathrm{HH}$ and he was therefore treated with testosterone gel with regression of specific manifestations but elevated hemoglobin and hematocrit values. Therefore, it was decided to switch to a restoration therapy with clomiphene citrate $25 \mathrm{mg} /$ die, which resulted in the resolution of symptoms without evident side effects. In a couple of months, the patient showed normalization of testosterone levels and increment of testicular volume. Since secondary hypogonadism is the consequence of an insufficient stimulation of the gonads by hypothalamic-pituitary axis, therapeutic approaches aimed to restore endogenous testosterone production should be considered in alternative to testosterone replacement, particularly if side effects intervene. Among these strategies, clomiphene citrate seems to have a high efficacy and safety profile also in the elderly with isolated $\mathrm{HH}$ and no evident pituitary lesion.

\section{Learning points:}

- Hypogonadism should always be assessed in patients with severe loss in BMD and undergo appropriate medical treatment.

- In hypogonadotropic hypogonadism, more approaches are available other than testosterone replacement therapy alone.

- In patients with severe late-onset central hypogonadism presenting with erythrocytosis even at low doses of replacement therapy, restoration therapy with clomiphene could prove to be an effective solution, particularly in patients with a reversible disruption of GNRH/gonadotropin functions.

- Clomiphene citrate increases gonadotropin levels and testicular volume and should therefore be considered in hypogonadal men who wish to remain fertile.

\section{Background}

This case describes the successful use of an offlabel therapy for hypogonadotropic hypogonadism determining osteoporosis, in which replacement therapy was contraindicated due to erythrocytosis.

\section{Case presentation}

C R, a 66-year-old man, came to the endocrinologist's attention for II grade obesity (he had gained $10 \mathrm{~kg}$ in the previous year) and symptoms of hypogonadism. He complained of low physical endurance, lack of libido 
and erectile deficit and depressed mood; he was never interested in fathering a child.

In his past medical history, he reported two major surgery procedures due to a colon-sigma carcinoma (at the age of 55 years) and a kidney malignant tumor (at the age of 59 years); for none of the two tumors he received radiotherapy and/or chemotherapy. Moreover, he had essential hypertension. In 2012, osteoporosis was diagnosed (femoral T-score: -1.52 ; vertebral T-score: -3.2) without evidence of skeletal fractures, and he was therefore prescribed alendronate, calcium and $25 \mathrm{OH}$ vitamin D supplementation.

At the time of our evaluation, two years later, femoral BMD was further decreased by $4.8 \%$ and vertebral BMD by $2 \%$, compared with the previous examination. Moreover, the patient underwent an X-ray imaging for back pain that showed for the first time a thoracic vertebral deformation, and a $7-\mathrm{cm}$ reduction in height was recorded. No familiarity for hypogonadism, pubertal delay, olfactory defect or osteoporosis was reported. He did not receive any medical treatment other than alendronate and vitamin D.

On physical examination, his height was $163 \mathrm{~cm}$, weight: $97 \mathrm{~kg}$, BMI: $36.5 \mathrm{~kg} / \mathrm{m}^{2}$, PA: $140 / 90 \mathrm{mmHg}$, FC: $76 \mathrm{bpm} r$, waist circumference: $123 \mathrm{~cm}$; he showed normal virilization, regular penis dimension and conformation. He did not show gynecomastia. Testes were partially retractile and reduced in volume $(12 \mathrm{~mL}$ right, $10 \mathrm{~mL}$ left) with normal consistency.

\section{Investigation}

The patient was therefore studied for hypogonadism and hormonal examinations proved $\mathrm{HH}$ : $\mathrm{LH}=2.9 \mathrm{U} / \mathrm{L}$; $\mathrm{FSH}=3.1 \mathrm{U} / \mathrm{L} ; \mathrm{PRL}=5.1 \mu \mathrm{g} / \mathrm{L} ;$ total testosterone $=3.4 \mathrm{nmol} / \mathrm{L}$ (9.9-27.8). He had normal kidney and liver function, normal calcium and phosphorous metabolism and no other hormonal alteration.

Testicular ultrasound showed small size but normal structure. Brief Smell Identification Test (Sensonics, Inc., USA) demonstrated partial deficit in his olfactory ability ( 8 correct identifications out of 12 tested odorants, normal range for age and sex $\geq 9$ ).

Genetic analyses were also performed using a targeted next-generation sequencing without proving any significant allelic variant in the known causal genes for isolated HH: ANOS1(KAL1), FGFR1, PROKR2, PROK2, GNRHR, GNRH1, GNRH2; KISS1, KISS1R, TAC3, TACR3, HS6ST1 (1).

MR imaging showed normal pituitary and olfactory bulbs.

\section{Treatment}

In consideration of hormonal values and symptomatic osteoporosis, the patient started replacement therapy with testosterone gel $2 \%, 40 \mathrm{mg} /$ day. Moreover, he was prescribed a tailored diet therapy.

During follow-up, C R demonstrated adequate androgen replacement with regression of the specific symptoms. Nevertheless, elevated hemoglobin and hematocrit values were noticed: $\mathrm{Hb}=19.1 \mathrm{~g} / \mathrm{dL}$, $\mathrm{Htc}=57.3 \%$, total testosterone $=15.22 \mathrm{nmol} / \mathrm{L}$.

Testosterone replacement therapy was then withdrawn and pulmonary causes of polyglobulia were excluded performing arterial blood gas analysis.

Since he was highly symptomatic and hemoglobin levels normalized, two months later, we started a new attempt with testosterone gel $2 \%, 10 \mathrm{mg} / \mathrm{day}$, associated with anti-platelet therapy. Despite low testosterone doses, relapse of erythrocytosis promptly occurred (hematocrit $52.2 \%$ ) and hormone therapy was again withdrawn.

After informed consent, the patient was then switched to an off-label trial therapy using clomiphene citrate (CC) $25 \mathrm{mg} /$ die in order to avoid these severe side effects.

\section{Outcome and follow-up}

Within ten weeks, the patient showed a progressive increase and normalization of testosterone levels during the following nine months in association with normal gonadotropin levels (Table 1).

Moreover, this treatment was effective in stimulating testicular growth up to normal values $(20 \mathrm{~mL}$ using Prader's orchidometer), but no gynecomastia was seen.

In addition, a DEXA performed after 2 years of treatment showed an initial increase of bone mineral density, after the reported inefficacy of bisphosphonates and vitamin D supplementation. The patient also reported an improved quality of life and mood with restoration of libido and spontaneous erections.

\section{Discussion}

The European Male Aging Study has demonstrated the $85 \%$ of late-onset hypogonadism to be hypogonadotropic (2). The current recommended therapy for both primary and secondary hypogonadism is testosterone replacement with proved beneficial effects on symptoms, even though it could induce infertility (3), hyperestrogenism (4) and erythrocytosis (5). 


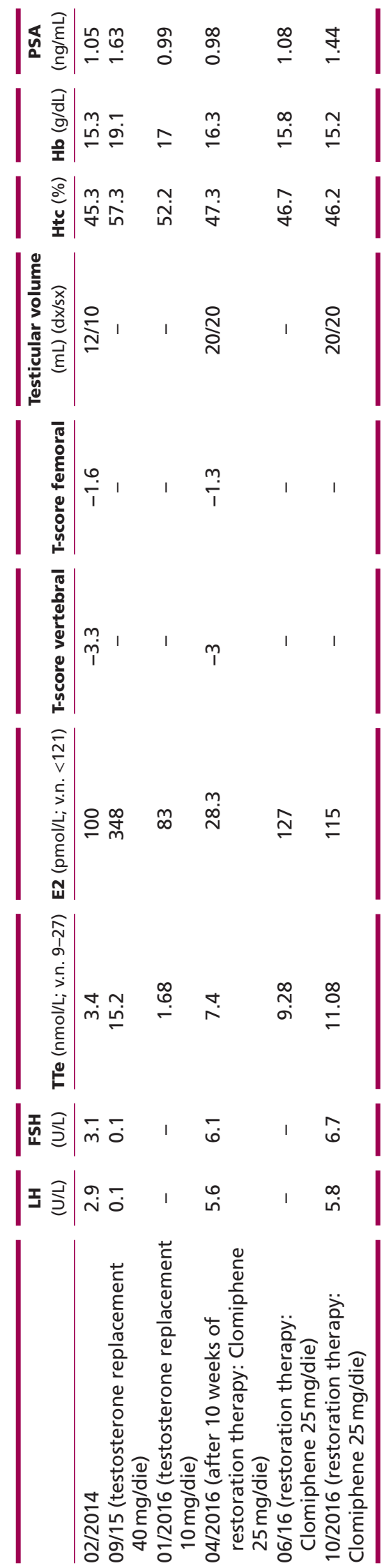

Testosterone therapy causes erythrocytosis via increased erythropoietin and suppressed hepcidin (5) and during replacement therapy, hemoglobin and hematocrit must be carefully evaluated since an increment is a common untoward effect. This effect is known to be more common using testosterone enantate intramuscular injections rather than testosterone undecanoate or gel formulations due to a worse pharmacokinetic and dynamic profile (6).

In this case, we reported even low-dose testosterone gel replacement therapy proved to be impracticable; in such patients with highly symptomatic isolated central hypogonadism, alternative therapeutic approaches should be considered $(7,8)$.

Although CC is an off-label therapy in male, we proposed its use in order to obtain reversal of the $\mathrm{HH}$ since it is less likely to give supra-physiological peaks of testosterone. CC is indeed cheaper than hCG and is a Selective Estrogen Receptor Modulator (SERM) that acts by removing central negative feedback of estrogens, thus resulting in increased GnRH pulses, consequent $\mathrm{LH}$ and FSH elevations and testicular stimulation (Fig. 1). This mechanism of action is particularly useful in male obesityrelated $\mathrm{HH}$ with an increased aromatase activity of the visceral adipose tissue. Indeed, in our patient, CC proved to be effective in restoring eugonadism and avoiding the serious side effect given by exogenous hormone therapy despite the patient was over 65 years.

CC therapy in HH has been demonstrated to increase testosterone and to positively affect bone mineral density with a good safety profile after three years (9).

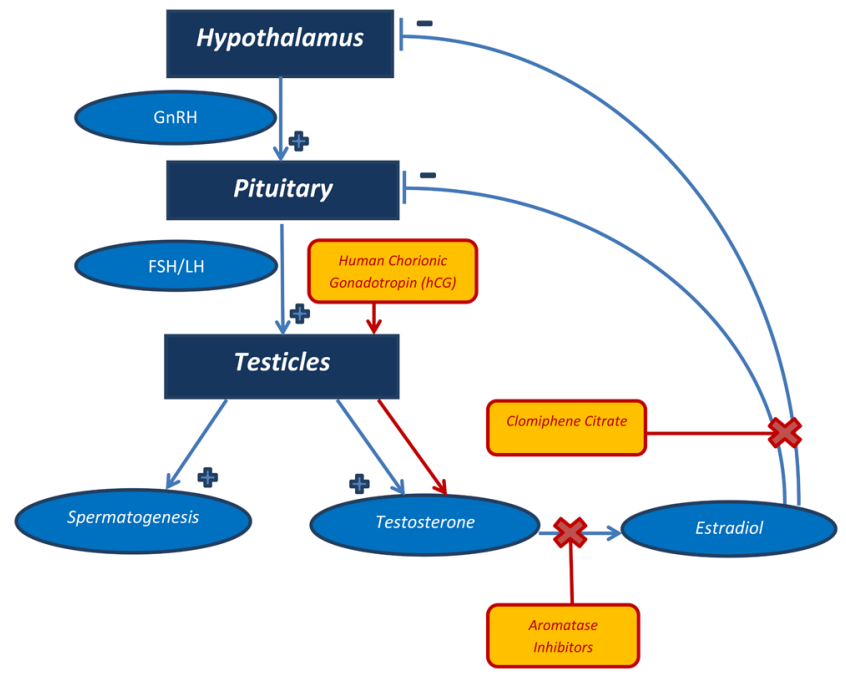

Figure 1

Mechanism of action of restoration therapies. 
Moreover, this SERM has been tested in male infertility with discordant results. However, even if its beneficial effects in idiopathic male infertility are still debated, it has a positive impact on hypogonadal infertile men (7) in contrast to testosterone replacement therapy that indeed reduces gonadal stimulation (6).

Interestingly, CC effectiveness has been questioned in elderly patients due to a limited efficacy compared with younger subjects. However, one study supporting this hypothesis was based on a small cohort of patients and the older subjects had elevated gonadotropin levels at baseline, whereas other papers documented only a minor symptomatic response attributable to end-organ disease as diabetes or other systemic pathologies $(9,10)$. Therefore, the lack of positive effect could be due to an underlying primary defect of the gonad or other causes affecting symptoms.

In conclusion, as secondary hypogonadism is the consequence of an insufficient stimulation of the gonads by hypothalamic-pituitary axis, new therapeutic approaches aimed to restore endogenous production of testosterone should be considered, especially in those patients in which testosterone replacement therapy is contraindicated due possible side effects. Among these strategies CC seems to have a high efficacy and safety profile (11). Thus, our study represents an additional support for the expansion of the CC indications to male $\mathrm{HH}$, particularly when hypogonadism is obesity related.

\section{Declaration of interest}

The authors declare that there is no conflict of interest that could be perceived as prejudicing the impartiality of the research reported.

\section{Funding}

This study was partially supported by funds from IRCCS Istituto Auxologico Italiano (05C901)

\section{Patient consent}

Authors declare to have obtained a written informed consent from the patient for the publication of the anonymous results concerning the clinical and genetic follow-up of his condition.
Author contribution statement

B C, C C, and M B has clinically followed the patient. B C, M B wrote the paper. L P supervised the study, revised and edited the manuscript.

\section{References}

1 Vezzoli V, Duminuco P, Bassi I, Guizzardi F, Persani L \& Bonomi M 2016 The complex genetic basis of congenital hypogonadotropic hypogonadism. Minerva Endocrinologica 41 223-239.

2 Tajar A, Forti G, O’Neill TW, Lee DM, Silman AJ, Finn JD, Bartfai G, Boonen S, Casanueva FF, Giwercman A, et al. 2010 Characteristics of secondary, primary, and compensated hypogonadism in aging men: evidence from the European Male Ageing Study. Journal of Clinical Endocrinology and Metabolism 95 1810-1818. (doi:10.1210/jc.2009-1796)

3 Samplaski MK, Loai Y, Wong K, Lo KC, Grober ED \& Jarvi KA 2014 Testosterone use in the male infertility population: prescribing patterns and effects on semen and hormonal parameters. Fertility and Sterility 101 64-69. (doi:10.1016/j.fertnstert.2013.09.003)

4 Borst SE \& Mulligan T 2007 Testosterone replacement therapy for older men. Clinical Interventions in Aging 2 561-566. (doi:10.2147/ CIA.S1609)

5 Bachman E, Travison TG, Basaria S, Davda MN, Guo W, Li M, Connor Westfall J, Bae H, Gordeuk V \& Bhasin S 2014 Testosterone induces erythrocytosis via increased erythropoietin and suppressed hepcidin: evidence for a new erythropoietin/hemoglobin set point. Journals of Gerontology: Series A, Biological Sciences and Medical Sciences 69 725-735. (doi:10.1093/gerona/glt154)

6 Rhoden EL \& Morgentaler A 2004 Risks of testosterone-replacement therapy and recommendations for monitoring. New England Journal of Medicine 350 482-492. (doi:10.1056/NEJMra022251)

7 McCullough A 2015 Alternatives to testosterone replacement: testosterone restoration. Asian Journal of Andrology 17 201-205. (doi:10.4103/1008-682X.143736)

8 Corona G, Rastrelli G, Vignozzi L \& Maggi M 2012 Emerging medication for the treatment of male hypogonadism. Expert Opinion on Emerging Drugs 17 239-259. (doi:10.1517/ 14728214.2012.683411)

9 Moskovic DJ, Katz DJ, Akhavan A, Park K \& Mulhall JP 2012 Clomiphene citrate is safe and effective for long-term management of hypogonadism. BJU International 110 1524-1528. (doi:10.1111/ j.1464-410X.2012.10968.x)

10 Tenover JS, Matsumoto AM, Plymate SR \& Bremner WJ 1987 The effects of aging in normal men on bioavailable testosterone and luteinizing hormone secretion: response to clomiphene citrate. Journal of Clinical Endocrinology and Metabolism 65 1118-1126. (doi:10.1210/jcem-65-6-1118)

11 Chandrapal JC, Nielson S, Patel DP, Zhang C, Presson AP, Brant WO, Myers JB \& Hotaling JM 2016 Characterising the safety of clomiphene citrate in male patients through prostate-specific antigen, haematocrit, and testosterone levels. BJU International 118 994-1000. (doi:10.1111/bju.13546)

Received in final form 23 May 2017

Accepted 7 June 2017 